\section{"Carnivorismo é uma civilização": vegetarianismo brasileiro e discursos sobre os animais, 1902-1940}

\author{
"Being a carnivore is \\ civilization:" Brazilian \\ vegetarianism and discourse \\ about animals, 1902-1940
}

Natascha Stefania Carvalho De Ostos ${ }^{i}$

i Pós-doutoranda, Instituto René Rachou/Fiocruz. Belo Horizonte - MG - Brasil

orcid.org/0000-0002-4531-1924

nataschaostos@hotmail.com

Recebido em 30 dez. 2020.

Aprovado em 29 abr. 2021.

http://dx.doi.org/10.1590/S0104-59702021000500002
OSTOS, Natascha Stefania Carvalho De. "Carnivorismo é uma civilização": vegetarianismo brasileiro e discursos sobre os animais, 1902-1940. História, Ciências, Saúde - Manguinhos, Rio de Janeiro, v.28, supl., dez. 2021, p.37-57.

Resumo

$\mathrm{O}$ artigo analisa discursos produzidos sobre os animais pelo movimento vegetariano brasileiro do início do século XX. Contextualiza a criação do movimento no país, situando argumentos científicos e morais que embasaram a defesa do vegetarianismo. Analisa os discursos que cotejavam humanos e animais em seus aspectos biológicos e comportamentais, e que consideravam a carne um elemento "contaminador" da natureza humana. Argumenta que a a defesa da vida animal feita pelos vegetarianos naquela época não significava, necessariamente, a abolição de hierarquias e assimetrias entre a humanidade e os demais seres vivos.

Palavras-chave: história; vegetarianismo; animais; natureza; saúde.

\section{Abstract}

This article analyzes discourse on animals from the Brazilian vegetarian movement during the early twentieth century. It provides context for the creation of this movement in the country, positioning scientific and moral arguments that were used to defend vegetarianism. Discourse that compared the biological and behavioral aspects of human and nonhuman animals and considered meat as an element that "contaminated" human nature was analyzed. We argue that the defense of animal life mounted by vegetarians at that time did not necessarily mean abolishing hierarchies and asymmetries between humans and other living beings.

Keywords: history; vegetarianism; animals; nature; health. 
$\mathrm{O}$ presente artigo pretende contribuir para a expansão dos estudos históricos sobre o vegetarianismo no Brasil a partir de um recorte específico, analisando como o movimento vegetariano do início do século XX pensava e situava os animais em seus discursos.

Ao empregar a expressão vegetarianismo, estamos nos referindo “à prática voluntária de abstenção de carne, com base em considerações religiosas, espirituais, éticas, de saúde ou ambientais" (Whorton, 2000, p.1553). ${ }^{1}$ Os estudos sobre o vegetarianismo se encontram bem desenvolvidos na historiografia internacional, transitando por ampla temporalidade e privilegiando diferentes ângulos analíticos. Um bom número deles se debruça sobre as doutrinas e os movimentos religiosos que prescreveram a abstenção de carne como forma de elevação espiritual, como é o caso de Tristam Stuart (2006), que, além de mapear seitas cristãs vegetarianas que surgiram na Inglaterra desde o século XVII, demonstrou como a colonização inglesa da Índia influenciou a disseminação dos ideais vegetarianos no país. Não por acaso, a Inglaterra se tornou o epicentro do movimento vegetariano no Ocidente, sendo palco da criação da primeira sociedade vegetariana de que se tem notícia, em 1847, que logo inspirou a fundação de congêneres em outros países. Dada a importância do século XIX como marco de expansão do vegetarianismo organizado, os historiadores têm dedicado especial atenção a esse período. James Gregory (2007) pesquisou o movimento na Grã-Bretanha da Era Vitoriana, demonstrando a amplitude de suas plataformas, que transitavam por questões religiosas, debate médico, defesa dos animais. Seu estudo enfatiza não tanto as prescrições alimentares, e sim a história social do movimento, sua conexão com o ambiente reformista da época (p.11). Trabalho pioneiro, referência para os pesquisadores do assunto, é a tese de Julia Twigg (1981), na qual a autora combina abordagens histórica, sociológica e antropológica para estudar o sistema de crenças e ideias que ancoraram o movimento vegetariano na Inglaterra entre 1847 e 1981, explorando as conexões entre vegetarianismo, feminismo, pacifismo e ambientalismo.

Esses e outros trabalhos abordam o lugar dos animais na estrutura argumentativa e programática do vegetarianismo histórico. Tristam Stuart (2006, p.39), remonta à Antiguidade para explicar como a filosofia de Pitágoras interditava o consumo de carne com base na crença da transfiguração das almas (segundo a qual o espírito humano poderia reencarnar em outras criaturas). Abrams (2000, p.1564) ressalta como as complexas doutrinas religiosas do hinduísmo e budismo, ao rejeitar a ingestão de carne, ajudaram a propagar preceitos de não violência para com os bichos. Arouna Quédraogo (2000, p.826) e Keith Thomas (1988, p.342-343) relatam a atuação, nos séculos XVII e XVIII, dos "vegetarianos espiritualistas", para os quais esse era o regime existente antes da expulsão do homem do paraíso, onde seres humanos e animais supostamente coabitavam em harmonia, sem consumir carne, de modo que a prática vegetariana seria uma forma de alcançar pureza espiritual. James Gregory (2007, p.88) demonstra como, na Era Vitoriana, a defesa dos bichos pelo movimento vegetariano inglês estava relacionada a novas sensibilidades urbanas, de rejeição da morte explícita e da crueldade.

No Brasil, o tema do vegetarianismo ainda não foi sistematicamente explorado pela historiografia. Pesquisadores de Portugal têm pontuado o assunto em meio a investigações sobre o movimento vegetariano português, historicamente ligado ao brasileiro. É o caso de Isabel Braga (2018), que estudou a criação de uma colônia naturista no Pará por 
ativistas vegetarianos portugueses em 1914. O presente artigo não pretende realizar uma história do vegetarianismo brasileiro ou de suas sociedades. Porém, tendo em vista a lacuna bibliográfica no que se refere à história do movimento, fez-se necessário mapear informações sobre a criação das primeiras sociedades vegetarianas do país, levantando nomes e grupos ligados à causa. A partir dessa contextualização analisamos os discursos produzidos pelo movimento vegetariano sobre os animais, de modo a compreender como a recusa em ingerir carne se interligava com as ideias que os ativistas tinham sobre os bichos, em comparação com os humanos.

Para fundamentar a análise utilizamos o conceito de discurso formulado por Michel Foucault (2004, p.122), isto é, um "conjunto de enunciados que se apoia em um mesmo sistema de formação". Para operar o trabalho analítico, algumas opções metodológicas se apresentaram: escolher uma obra que tratasse do assunto; selecionar um autor vegetariano e escrutinar suas falas; recortar um grupo social interessado no tema. Tais vias enquadrariam bem o objeto, mas, a nosso ver, ao fechar o ângulo de análise isolaríamos discursos cuja especificidade não reside no pioneirismo ou na excepcionalidade das falas, e sim nas relações que entrecruzavam esses enunciados, permitindo que os diversos atores envolvidos no movimento vegetariano (médicos, militares, jornalistas, educadores) entendessem os animais como uma temática em rede, integrada ao conjunto argumentativo dos ativistas, expressa a partir de domínios variados, da ciência/saberes médicos à moral/religião. Nada impede que esses domínios sejam analisados isoladamente, mas optamos por demonstrar como tais enunciados, "dispersos e heterogêneos", coexistiram a partir de um "nexo de regularidade" (Foucault, 2004, p.39, 54). As falas sobre os animais não estavam compartimentadas em uma rubrica, elas se espraiavam pela argumentação científica, médica e moral do movimento vegetariano; o que não quer dizer que eram aleatórias. Ao tratar dos animais os discursos vegetarianos estavam, também, falando do humano, e era esse ponto, a tensão comparativa entre humano/animal, o elemento recorrente dessas diferentes manifestações discursivas.

O corpo documental que ancora essa pesquisa está baseado em dois conjuntos principais. O primeiro consiste em publicações editadas por sociedades vegetarianas ou seus membros. Foram encontradas: revista $\mathrm{O}$ Bem, editada por integrante da Sociedade Vegetariana Brasileira, no Rio de Janeiro, provavelmente a partir de 1924; O Naturista, lançada em 1918, em São Luís, Maranhão, pelo Núcleo Naturista Maranhense; e $O$ Naturista, fundada em 1936, pertencente à Sociedade Naturista Brasileira, entidade criada na cidade do Rio de Janeiro em 1934. Esse material tem caráter lacunar e mostrou-se insuficiente para subsidiar a análise. Não localizamos registros burocráticos das sociedades, mas conseguimos, por meio das informações contidas nas revistas, identificar outras organizações vegetarianas e levantar importantes nomes do movimento. Como o ambiente intelectual do período era marcado pelas discussões na imprensa, cruzamos as datas de criação das entidades e os nomes dos sócios, localizando uma série de artigos, notícias, transcrição de palestras em jornais e revistas, material que configura nosso segundo conjunto de fontes.

Claro está que as revistas editadas pelas sociedades estão imbuídas da defesa dos programas vegetarianos, e seu valor reside justamente na possibilidade de mapear as ideias 
que encampavam. O conjunto documental reunido por meio da imprensa é composto de um conteúdo noticioso (informações sobre criação, iniciativas do movimento, investidura de diretorias, transcrição de estatutos) e um conteúdo opinativo sobre o vegetarianismo. É sabido, como alerta Tania de Luca (2008, p.130), que o perfil editorial dos impressos influencia a seleção dos conteúdos, de acordo com interesses econômicos e políticos dos veículos. Porém, alguns conteúdos estão mais sujeitos a esse crivo, outros menos. No caso do vegetarianismo, as notícias referentes ao assunto não tinham, naquele momento, forte repercussão política ou econômica para justificar amparo ou repúdio editorial dessa pauta pelos impressos. As notícias e os artigos sobre a questão vegetariana se repetiam em periódicos com linhas editoriais diversas, portanto, no caso dessa pesquisa, a investigação documental por meio da imprensa ganha relevo no viés que Tania de Luca (2008, p.32) chamou de "as funções sociais [dos] impressos". Isso quer dizer que, mesmo considerando as diferenças editoriais entre os periódicos, as primeiras décadas do século XX testemunharam uma imprensa marcada, segundo Roberto Ventura (1991, p.148, 152), pela disputa de teorias por meio do "discurso da polêmica", tornando jornais e revistas instrumentos privilegiados para conferir visibilidade e exposição pública às ideias de vários grupos sociais, como os ativistas vegetarianos.

Selecionamos 1902 como marco temporal inicial da pesquisa em razão de que, nesse ano, foi publicado o panfleto "Positivismo e vegetarismo", pela Igreja Positivista do Brasil. Consideramos esse impresso uma baliza importante, pois, diferentemente das teses médicas sobre o vegetarianismo apresentadas no Brasil em fins do século XIX, a argumentação do opúsculo se baseava na defesa, já na primeira página, do que definiu como a "superioridade moral de um regime do qual fosse excluída toda espécie de carne" (Lemos, nov. 1902, p.1). O panfleto representa a entrada na cena pública do debate ético e moral sobre o vegetarianismo, capitaneado por ala do positivismo, movimento de inegável influência no meio intelectual brasileiro. Nos anos seguintes, as sociedades vegetarianas aglutinariam valores e princípios morais semelhantes, normatizando a ingestão de carne, transformando o vegetarianismo em uma causa autônoma, a ser defendida e disseminada.

Limitamos a análise a 1940 pelo fato de que, no fim da década de 1930, escassearam as manifestações públicas dos principais nomes ligados ao movimento vegetariano organizado no início do século XX. As motivações podem ser variadas, falecimento dessas pessoas, encerramento das organizações, perda de espaço nos periódicos. Assim, o estudo do movimento vegetariano após 1940 remete a contexto específico, demandando pesquisa que não cabe nos limites deste artigo.

Por fim, é importante ressaltar que, como alerta Michel Foucault (2004, p.124), "a análise enunciativa", configurada nos discursos, é também "uma análise histórica", deve ser qualificada no tempo e no espaço, remeter ao status dos indivíduos que falam, aos lugares que ocupam. A descrição integra a análise histórica, por isso propomos, primeiramente, contextualizar a criação do movimento vegetariano no Brasil, mapear seus principais domínios argumentativos e os grupos que se destacaram no interesse pela causa. 


\section{O movimento vegetariano no Brasil das primeiras décadas do século $\mathrm{XX}$}

O termo "vegetariano" foi disseminado na esteira da fundação da primeira sociedade vegetariana, na Inglaterra, em 1847 (Gregory, 2007, p.1). O vegetarianismo, como conceito, está longe de expressar homogeneidade histórica ou unidade de pensamento, mas a partir do século XIX configurou-se um movimento organizado de feição laica, que se esforçou para unificar pautas e propagar sua agenda ao público em geral. A defesa do vegetarianismo remetia, então, a concepções higienistas e de regeneração social, como instrumento para a formação de uma sociedade pacífica, física e moralmente sã. As sociedades vegetarianas não eram clubes que visavam apenas à convivência entre os membros. Tinham antes como principal objetivo convencer a opinião pública da superioridade de suas práticas, de modo que grande parte das atividades era voltada para o proselitismo da causa, tendo como alvo o público externo. Como pontua James Whorton (2000, p.1533), a história do vegetarianismo é também a história dos argumentos mobilizados para justificar e divulgar esse regime.

Normalmente, as sociedades vegetarianas eram organizadas a partir de uma reunião inaugural, por vezes divulgada na imprensa, conclamando interessados a comparecer. Elaborava-se um estatuto e elegia-se diretoria, com cargos como presidente, tesoureiro, secretário, com mandato determinado. A filiação era livre, desde que se respeitasse o programa da entidade, e as atividades se desenvolviam em encontros periódicos. No Brasil, a primeira sociedade vegetariana de que temos notícia é a Sociedade Naturista Brasileira, criada em 1913, na capital federal, cuja denominação foi alterada, em 1916, para Sociedade Vegetariana Brasileira (SVB) (Pelas associações..., 19 dez. 1916, p.5). Em 1916, criou-se, em São Paulo, a Sociedade Renascença Naturista (Gazeta de Notícias, 16 jan. 1916, p.8), e, em 1917, fundou-se, na cidade de São Luís do Maranhão, o Núcleo Naturista Maranhense (Núcleo..., 2 out. 1917, p.4), entre outras. Não é nosso objetivo fazer um inventário das organizações, e sim evidenciar como a criação de várias sociedades do tipo, naquele período, apontava para o interesse no assunto. Na ausência de registros administrativos das agremiações não temos amostras suficientes para realizar uma prosopografia acurada dos membros. Os nomes mais facilmente localizados são de integrantes das diretorias, que falavam em nome da causa. Porém, mesmo no caso dos gestores, nem sempre foi possível qualificar os envolvidos. O que podemos afirmar é que entre os dirigentes das entidades sobressaíam médicos e militares, pois seus títulos e patentes eram mencionados.

Uma grande influência para a criação das primeiras sociedades vegetarianas brasileiras foi a Sociedade Vegetariana de Portugal, fundada em 1911, no Porto, dirigida pelo médico Amílcar de Sousa, que mesclava argumentos morais na defesa do regime vegetariano com a mobilização de princípios científicos (Braga, 2018, p.660, 663). Membros dessa sociedade estabeleceram uma colônia naturista no Pará, em 1914, que durou pouco tempo, em razão de dificuldades de adaptação à natureza local (p.667, 669). Outra influência foi o russo Eliezer Kamenesky, figura esotérica, que vestia túnicas, tinha barba e cabelos longos, foi ator e viveu em Portugal. Ele propunha que o vegetarianismo era conforme a leis divinas e da natureza, aproximando o ser humano da perfeição espiritual (Braga, 2018, p.664; Um hóspede..., 4 jan. 1918, p.1). 
Assim, o vegetarianismo comportava diferentes correntes, nomenclaturas e práticas, cujas definições na documentação são instáveis, variando conforme a perspectiva dos comentadores. Muitas das primeiras sociedades vegetarianas foram inicialmente denominadas naturistas. Essa palavra correspondia, no início do século XX, a um programa em defesa de uma vida saudável que incluiria, além do regime vegetariano, práticas de cuidado com o corpo e contato com a natureza, como: banhos em rios e no mar, exposição ao sol, uso de roupas leves, habitações ventiladas, exercícios físicos, passeios ao ar livre (Barthe-Deloizy, 2003, p.49). Na imprensa, os termos naturista e vegetariano eram quase sempre usados como sinônimos. Nos comentários dos ativistas, a palavra naturismo expressava um princípio de vida: "Ser naturista é viver em harmonia com as leis da Natureza, repudiando o artifício" (SNB, 16 dez. 1913, p.1). Independentemente da denominação, a pauta principal das sociedades era a defesa do vegetarianismo.

Ao lado das expressões naturismo e vegetarianismo, outras sobressaíam, como "vegetarismo" e "vegetalismo", também usadas como sinônimos. Raramente se fazia diferenciação entre elas, como no caso do médico Oscar de Souza, que em palestra detalhou as nomenclaturas, indicando suas especificidades dietéticas. "O vegetarismo tolera alimentos animais, mas não aceita a carne ... é nestas condições o regime ovo-lacto-vegetariano". Já a "forma rigorosa do vegetarismo não compreende senão os alimentos vegetais", ${ }^{2}$ chamandose vegetalismo. "O fruitarismo ou frugivorismo é um caso particular do vegetalismo", em que o praticante se alimenta de frutas e que, segundo o autor, não aceitaria o cozimento dos produtos (Associações..., 24 out. 1917, p.3). A classificação acima é incomum nas fontes. Quando se falava de dieta vegetariana, o ponto comum era a abstenção de carne, mas as práticas abrigadas sob o guarda-chuva do vegetarianismo eram variadas, indicando graus de restrição quanto aos produtos ingeridos (alguns permitiam ovos e produtos lácteos) e às formas de preparo.

Os propagandistas se empenhavam, porém, em esclarecer que o vegetarianismo não se resumia à adoção de hábitos alimentares. Os programas das sociedades implicavam um modo de vida - que incluía o cuidado de si -, mas que propunha, sobretudo, a adesão a um projeto de sociedade. O impacto individual do vegetarianismo (físico e moral) deveria desencadear mudanças sociais. Como sintetizou um propagandista da época, o vegetarianismo "Não é um código de receitas" (Olandim, nov. 1924). Para os adeptos do movimento, a "superioridade" da prática sustentava-se em dois princípios: "ciência e moral" (SNB, 16 dez. 1913, p.1). O movimento vegetariano dialogou intensamente com as ciências e as teorias médicas que disputavam espaço no debate público e lutavam para afirmar-se como verdades científicas. Segundo Dominichi Sá (2006, p.14), nesse período, "Homens de ciência ganharam respeitáveis ares públicos de experimentação e observação da 'realidade'". Com a proclamação da República desejava-se não apenas mudar o regime político como também inaugurar um Brasil moderno, alinhado com os progressos tecnológicos e com as novas teorias científicas que levariam ao desenvolvimento do país. Nesse contexto, os médicos assumiram o papel de mediadores do conhecimento, assessorando não apenas os pacientes, mas também o Estado e a sociedade na implantação de iniciativas para a melhoria da saúde pública.

De acordo com Vasconcelos (2007, p.200), os hábitos alimentares da população brasileira e suas consequências para a saúde já chamavam a atenção dos saberes médicos desde meados 
do século XIX, resultando na produção de estudos sobre padrões alimentares da sociedade e seus fatores determinantes. O autor assinala que, no período de 1900 a 1929, surgiu nas faculdades de medicina a área da higiene alimentar, que já remetia a discussões da fisiologia e microbiologia, mas que ainda ligava a alimentação a fatores raciais e climáticos (p.202). A comunidade médica nacional demonstrou interesse pela alimentação vegetariana desde o fim do século XIX, quando foi defendida tese, em 1895, na Faculdade de Medicina do Rio de Janeiro, intitulada Vegetarismo (Boletim..., set. 1895, p.266). As discussões sobre o vegetarianismo nas publicações acadêmicas vinham sob rubricas como "Regime alimentar", "Higiene dietética", "Noções de higiene alimentar" (SMC, 20 nov. 1915, p.350; Armbrust, 5 fev. 1916, p.45), inserindo-se em um contexto mais amplo, que buscava compreender os fatores "determinantes" na constituição da população brasileira, remetendo a aspectos biológicos, de saúde e doença, mas também a questões históricas, raciais e sociológicas. Eronides Lima (1998, p.62-63) esclarece que no país, até por volta de 1934, os estudos na área da alimentação eram "marcados pelo ensaísmo, estavam dispersos no interior de campos afins, como a sociologia, a antropologia, a higiene, a puericultura etc., num momento em que também não existia o espaço específico no interior do qual o saber sobre nutrição adquirisse autonomia". A autora ressalta que, no Brasil das primeiras décadas do século XX, os estudos da nutrição estavam em descompasso "em relação aos países adiantados", pela feição empirista "dos estudos até então desenvolvidos, sem o caráter sistemático de um método único por meio do qual teoria e 'empiria' se aproximassem" (Lima, 1998, p.62).

Esse é um ponto central, pois, no início do século XX, o debate médico sobre a dieta vegetariana mesclava teorias modernas com discursos de caráter ensaístico. Os autores, alguns declaradamente vegetarianos, transitavam entre estudos fundados em conceitos e método, e afirmações impressionistas sobre a alimentação e seu impacto individual/social. Assim, nessa época, a discussão a respeito da dieta vegetariana inseria-se no contexto de transição das ciências da nutrição, em que ideias generalistas e assistemáticas conviviam com pesquisas metodologicamente organizadas. Segundo Lima (1998, p.63), nesse momento, o debate científico sobre a alimentação foi marcado por "Um fato novo ... a fisiologia da nutrição", dedicada a investigar os processos bioquímicos e físicos da ingestão. Os registros históricos corroboram a importância dessa área nos debates sobre a dieta vegetariana. Partindo dos mecanismos fisiológicos da ingestão, os clínicos discorriam sobre como o consumo de carne/vegetais produzia efeitos gastrointestinais, impactava a absorção de nutrientes, a ação das enzimas digestivas e o metabolismo.

Na concepção dos médicos simpatizantes do movimento, a alimentação era "uma questão de fisiologia", e o vegetarianismo era tido como um "regime certificado pela ciência" (Associações..., 24 out. 1917, p.3). Em 1917, a SVB patrocinou um ciclo de conferências públicas, "distintos clínicos" falaram sobre temáticas caras ao vegetarianismo (Iniciativa..., 17 out. 1917, p.2). Um dos palestrantes foi o doutor Frederico Oscar de Sousa, lente de fisiologia da Faculdade de Medicina do Rio de Janeiro, membro da Academia Nacional de Medicina (Sousa, 16 ago. 1941, p.576). Outro orador foi o doutor Plácido Barbosa, "reputado clínico, higienista", médico da Saúde Pública (SVB, 16 nov. 1917, p.4). Mais um nome de destaque foi o de Antônio Pacheco Leão, médico e diretor do Jardim Botânico, "sócio efetivo da Sociedade" (SVB, 25 jul. 1917, p.8). Mesmo que nem todos esses profissionais tenham 
sido membros da SVB, a disposição de ministrar palestras para a entidade demonstrava simpatia pela causa e alguma concordância com seus princípios. Fato importante é que nesse período a agremiação era dirigida por médico de prestígio, Gustavo Armbrust (5 fev. 1916, p.45), livre-docente da Faculdade de Medicina do Rio de Janeiro, colaborador efetivo da revista $O$ Brasil Médico, em que publicou estudos e revisão de literatura sobre regime vegetariano. Adentrando o campo da fisiologia, o clínico propunha a eliminação da carne do cardápio, alegando que ela pouco nutria e ainda causaria problemas físicos, pois no processo de digestão produziria resíduos tóxicos para o organismo, como "ácidos úrico, sulfúrico e fosfórico" (12 fev. 1916, p.54).

Além da fisiologia, o debate sobre qual seria a "verdadeira" dieta humana buscava provas nos hábitos alimentares do homem pré-histórico e na biologia, como na comparação da dentição dos homens com os carnívoros e herbívoros. A discussão ocorria no âmbito das publicações científicas e das associações médicas, como a Sociedade de Medicina e Cirurgia do Rio de Janeiro. Os defensores do vegetarianismo ressaltavam a suposta evidência de que os humanos, por terem caninos curtos e mandíbulas fracas, eram "naturalmente frugíveros, como os macacos" (Armbrust, 12 fev. 1916, p.54); que "O homem não é, aliás, carnívoro por natureza: falta-lhe para isso não só a dentição como as glândulas eliminadoras dos carnívoros" (18 dez. 1915, p.380-381).

A comunidade médica normalmente enfatizava os benefícios de uma "dieta mista", assinalando que a proteína animal era importante para a saúde (Dr. Jacobson, 12 nov. 1914, p.2). Os clínicos favoráveis à ingestão da carne não eram contrários à prescrição de um regime vegetariano como terapêutica, por exemplo, em quadros intestinais (Peixoto, 22 abr. 1908, p.156). Para esses médicos, ser a favor da carne na dieta não expressava, geralmente, uma militância. Em um trabalho de revisão sobre os hábitos alimentares do "homem primitivo", publicado na revista O Brasil Médico, o autor defendeu a ideia de que os ancestrais humanos eram preferencialmente carnívoros. Ao finalizar o texto ele instou a comunidade científica a debater o assunto de forma objetiva, sem paixões.

É certo que a hipótese é excelente método de trabalho, uma vez fundamentada em dados já adquiridos ou plausíveis: ou entrevê ou descobre a verdade. E enquanto não surge ela incontestável e evidente, é permitido o debate; este, no entanto, no terreno elevado e sereno das ideias, sem azedumes nem agressões a qualquer contradita, feitio de polêmica aliás sem guarida nesta revista (S.M.B., 29 fev. 1936, p.198).

O trecho revela a feição "quente" da discussão na época. O autor pedia que o debate ocorresse dentro de balizas científicas (hipótese, método, dados, provas, revisão e argumentação entre pares), e não por meio de polêmicas e crenças. O fato de o autor achar necessário fazer tal apelo evidencia que esses princípios nem sempre eram seguidos, mesmo em publicações de ciência. Mesclada à argumentação de cunho científico, os médicos ativistas por vezes lançavam mão de justificativas morais e opinativas para defender suas ideias, com afirmações que se assemelhavam a slogans, como na seguinte passagem, também na revista O Brasil Médico: "A carne é muito mais excitante do que nutritiva", assemelhandose a "outros excitantes, tais como o álcool, o fumo, a morfina" (Armbrust, 18 dez. 1915, p.380). Nesse período, o vegetarianismo era tema do debate científico, objeto de teses, artigos 
e palestras, mas a discussão entre os profissionais das ciências médicas se dava, também, na tensão entre posições científicas e o ativismo, nem sempre claramente separados.

Outra categoria profissional presente entre os dirigentes das sociedades vegetarianas brasileiras era a militar. A SVB contou com os generais Raymundo Seidl e Antonio Aranha, comandante Cícero dos Santos, capitão Francisco Jaguaribe de Mattos etc. (Santos, 1937, p.30-31). O último, formado na Escola Militar do Rio de Janeiro, foi influenciado pelas ideias positivistas (Bernardino, 2016, p.1) e chegou a presidente da entidade. Os militares brasileiros, cuja formação era de caráter técnico e que lidavam com problemas de engenharia, geografia, cartografia, foram atraídos pelo positivismo e por sua valorização das ciências utilitárias. Além do mais, tal filosofia, segundo Angela Alonso (1995, p.15), se alinhava com a "missão salvadora da pátria" dos militares, de "vertente modernizadora". Francisco Jaguaribe era cartógrafo e trabalhou no Escritório Central da Comissão Rondon. Em 1919 jornais noticiaram a partida do capitão para Mato Grosso, como "chefe técnico da Comissão Rondon", sendo-lhe oferecido jantar de despedida pela SVB (Jantar, 15 nov. 1919, p.7).

A relação entre militares, positivismo e vegetarianismo é importante em razão de que uma ala do positivismo brasileiro era programaticamente vegetariana. Em 1902, Miguel Lemos, líder da Igreja Positivista do Brasil, publicou panfleto intitulado "Positivismo e vegetarismo". Na circular, Lemos (nov. 1902, p.8) explica que, apesar de Auguste Comte não preconizar essa dieta, ele se convenceu da sua superioridade, afirmando que se Comte estivesse vivo, à luz das novas evidências do "movimento vegetariano, prático e científico", ele teria aderido aos seus princípios. No texto ele menciona que o colega Teixeira Mendes também adotou o regime, "aceitou como eu a incorporação desta reforma no Positivismo, invocando os mesmos motivos morais e religiosos" (p.10), mas que os membros da Igreja não seriam obrigados a aderir ao preceito. No documento, Miguel Lemos argumenta que o vegetarianismo favorecia o altruísmo, "de maneira a suprimir totalmente o cruel sacrifício dos nossos companheiros animais, tão alevantados pela nossa doutrina" (p.1). Sobre a não imposição do vegetarianismo aos seguidores da Igreja, essa informação é contestada por Trajano Carneiro (30 set. 1993, p.19), nascido em família positivista. Ele declarou que existia pressão para que os membros aderissem às normas, "Havia um grande número de positivistas vegetarianos. ... Comer carne era quase que um pecado".

$\mathrm{O}$ vegetarianismo positivista não se preocupava tanto com a nutrição, e sim com as implicações morais da ingestão de carne pelo ser humano. Segundo o referido panfleto, mesmo a alimentação vegetariana sendo "vantajosa do ponto de vista físico", esse era um "aspecto secundário" diante do que qualificou como as "desvantagens morais inerentes aos hábitos carnívoros", e que "tais questões não podem ser decididas em última instância pela Biologia, mas pela Moral" (Lemos, nov. 1902, p.2, 7). Diante da incontestável influência do positivismo sobre a camada militar brasileira, não é de estranhar a presença desse grupo nos quadros das sociedades vegetarianas. Nos discursos das entidades encontramos linguagem semelhante à do positivismo, mesclando ciência e moral. O tenente Cícero dos Santos afirmou que a Sociedade Naturista estava "fundada nas normas de Amor à Humanidade", expressão cara ao positivismo (SNB, 16 dez. 1913, p.1).

Assim, além do seu caráter cientificista, o movimento vegetariano afirmou rígidos princípios morais, combatendo o consumo de álcool, o fumo e, em alguns casos, até o café. 
A carne era considerada alimento tóxico, por fazer mal à saúde e pelo suposto efeito negativo no caráter das pessoas, "veneno dissimulado, um excitante perigoso que leva à violência e às paixões" (Corton, nov. 1924). Os ativistas condenavam tudo que fosse artificial, "Só é puro e bom o produto que nos vem da Natureza sem transformação por parte do homem" (Naturismo, 24 jun. 1936, p.6). A natureza era compreendida como fonte de bem-estar físico e moral, fornecendo o padrão para o comportamento humano. Mary Douglas (1976, p.14) observa que, em muitas culturas, as leis da natureza são introduzidas para sancionar um código moral, de modo que doenças, ou outro fenômeno físico negativo, são interpretadas como punição pela desobediência a um preceito moral. No caso dos discursos do movimento vegetariano, as leis da natureza eram os próprios preceitos morais, fornecendo modelos de conduta para indivíduos e sociedade. Obviamente, essa natureza era tida como transparente, podendo ser apreendida de modo direto pela observação científica. A moralidade do mundo natural residiria no caráter incontornável de suas normas e organização. As invenções humanas e os estilos de vida que agredissem a ordem natural eram perigosos, por isso, moralmente condenáveis. Alguns adeptos do vegetarianismo defendiam sua forma mais "pura", o crudismo, que recusava o cozimento da comida: "No primeiro "fogo" que se acendeu para fazer o "alimento" humano, nasceu a decadência figenética [sic] do homem" (Santos, 24 jun. 1936, p.10). A carne, acima de todos os alimentos, representava o desvio da humanidade da natureza, uma anomalia, pois, para os ativistas, se comer carne fosse natural, o homem poderia consumi-la crua.

Desse modo, para os vegetarianos da época, a exclusão da carne da dieta estava alinhada com a ciência e os saberes médicos, justificada na organização fisiológica e evolutiva do ser humano. Mas também se baseava em princípios morais, na crença de que o consumo de carne gerava atitudes negativas, perigosas para indivíduos e sociedade. Esses dois fundamentos, científico e moral, também confluíam nos discursos vegetarianos sobre os animais. Sobressaíam as comparações biológicas e comportamentais entre os seres humanos e os bichos, na feição de carnívoros e herbívoros. Defendia-se o direito à vida dos animais, mas mantinham-se as assimetrias que hierarquizavam a humanidade e os demais seres vivos.

\section{Carne, mais do que um alimento: animalidade e humanidade no debate vegetariano}

Como afirma Bezerra (2012, p.158-159), adentrar o campo da alimentação e da nutrição é lidar com a historicidade das práticas alimentares, levando em conta aspectos biológicos, dimensões sociais e culturais. De acordo com Maciel (2004, p.26), "a alimentação refere-se a um conjunto de substâncias que uma pessoa ou um grupo costuma ingerir", mas também engloba modos de produção, formas de preparo, costumes. No que diz respeito à história do consumo de carne no Brasil existem muitas variáveis, sendo uma delas as diferenças regionais. Faltam estatísticas contínuas, mas para o período em questão temos dados do Anuário estatístico do Brasil. Em 1909, o Distrito Federal (cidade do Rio de Janeiro), abateu 178.572 bovinos, representando $10,63 \%$ do abate total desses animais no país. Comparativamente, o estado de São Paulo matou 173.192 cabeças no mesmo ano. Já o estado do Rio Grande do Sul abateu a impressionante cifra de 741.706 bovinos em 1909, 44,14\% do total nacional. Tais números são estimativas, pois dependiam de dados repassados por estados e municípios, e 
referiam-se a atividades legalizadas. Em 1909, o quilo de carne nos matadouros do Distrito Federal custava, em média, \$725; no Rio Grande do Sul, \$385 (menor valor médio do país), e no Amazonas, 1\$969, maior valor médio (Brasil, 1917, p.6-7, 13).

As informações apontam que o consumo de carne dependia de muitos fatores. O Distrito Federal, pelo contingente populacional e pela concentração de atividades econômicas, abatia número de bovinos comparável a um estado inteiro da federação. Já no Rio Grande do Sul, com sua tradição de criação de rebanhos desde o período colonial, a carne era abundante, e o charque (carne-seca) era produto fundamental da economia local, abastecendo mercado interno e externo (Vargas, 2014). Ainda sobre as diferenças regionais, o fato de que, em 1909, o Amazonas apresentava o maior valor médio do quilo de carne bovina do país vai ao encontro dos escritos clássicos de Josué de Castro (1984, p.66-68), publicado originalmente em 1946, que caracterizou a região como historicamente de difícil criação de gado. O rebanho local, pequeno e pouco produtivo, determinaria a escassez da carne bovina e seu alto preço. No período de 1908-1909, o valor médio da carne de boi nos matadouros do Brasil foi de "550 réis por quilo" (Brasil, 1917, p.XIV). Localizamos dados oficiais sobre o consumo de carne apenas para o Distrito Federal, onde, em 1909, o consumo de carne verde (fresca) bovina era de 45 quilos por habitante (Brasil, 1917, p.XLV), número muito expressivo. Infelizmente, a compilação das estatísticas foi interrompida, sendo retomada apenas na década de 1930.

De acordo com Chris Otter (2013, p.6), nos últimos trezentos anos o mundo ocidental passou por uma "transição nutricional", marcada pelo aumento do consumo de proteína animal, açúcares e gorduras. Esse processo não foi homogêneo, dependendo de fatores como nível de industrialização e urbanização. Porém, mesmo com o aprimoramento das técnicas de criação animal, principalmente a partir do século XIX, permitindo maior consumo de carne pelas camadas pobres (Fiddes, 2004, p.23), o produto continuou de acesso limitado. Assim, diferenças de classe também influenciavam a ingestão do alimento, de modo que a percepção que os ativistas vegetarianos tinham de que o brasileiro comia muita carne informa mais sobre o pertencimento social do grupo, agregando pessoas das camadas médias.

O debate sobre o vegetarianismo não envolve apenas uma opção dietética; ele remete a visões de mundo, ética, percepções sobre natureza e cultura, conceitos de humano e animal, de forma que, como pontua Lévi-Strauss (2009, p.211), não é de surpreender que "matar seres vivos para se alimentar coloque aos humanos, tenham eles consciência ou não desse fato, um problema filosófico que todas as sociedades tentaram resolver". Assim, mesmo quando o destino dos bichos é o abate, eles são criados, cuidados, circulam e morrem participando de processos sociais e históricos complexos (Rocha, 2020, p.60). O movimento vegetarianista brasileiro colocou em cena um fato básico, que a carne é o corpo, ou parte do corpo, de um animal, destinado ao consumo humano (Fiddes, 2004, p.3). Nos discursos vegetarianos da época, os animais apareciam na sua dimensão representacional (concepção humana sobre os bichos), mas sempre em diálogo com a materialidade, o "animal real", corpo-carne, promovendo o que Erica Fudge (2002, p.44) designou como "a ligação da carne com o animal da qual ela se originou". Ao ressaltar essa ligação, os discursos vegetarianos trouxeram para a cena pública questões desconfortáveis, apontando a presença animal na mesa e debatendo as implicações éticas desse fato. 
A defesa dos animais não era o argumento central na propaganda do movimento vegetariano do período, mas estava sempre presente. Historicamente, a correlação entre movimento vegetariano e discurso de proteção animal não é algo dado, ganhando aderência à medida que aumentava na sociedade o interesse pela causa animal. Sempre existiu, porém, a correlação entre abstenção de carne e a convicção de que matar animais é algo errado. Essa afirmação parece contraditória com o exposto acima, mas fato é que, até o século XIX, as premissas desse discurso eram predominantemente religiosas, como no caso de Jacob Böhme (1575-1624), cujos preceitos ditavam que matar qualquer ser vivo rompia a união mística com Deus (Quédraogo, 2000, p.826-827). Tanto os defensores do vegetarianismo quanto os do carnivorismo mobilizavam passagens bíblicas para fundamentar suas posições. Como, entretanto, observa Thomas (1988, p.353), "num mundo leigo, os argumentos baseados somente nas Escrituras, mostrar-se-iam cada vez menos eficazes". Ao lado das alegações religiosas emergiam outros argumentos de caráter antropocêntrico (comer carne faria mal à saúde humana, estimularia a violência etc.), mas também ganhava espessura o discurso ético, defendendo que todo ser vivo teria direto à vida e que os animais possuíam valor intrínseco. Aleixo Alves de Souza, presidente da Sociedade Naturista Brasileira, denunciava o "absurdo de que os animais são 'coisas' postas à mercê dos homens". Para o ativista, contudo, a atribuição de valor intrínseco aos animais não significava equiparação ao ser humano; o mundo natural seria composto de hierarquias: "Os animais são ... irmãos dos homens, embora em uma situação de menor desenvolvimento na escala dos seres dotados de vida ... as árvores ... na escala dos seres sensíveis a elas caiba uma situação ainda inferior à dos animais" (Souza, 11 out. 1931, p.18). Classificavam-se os viventes de acordo com o grau de sensibilidade, e isso determinaria se eles poderiam servir de alimento, e outros fins, para os humanos.

Encontramos correlações entre o movimento vegetariano da época e as sociedades protetoras dos animais, existentes no Brasil desde o fim do século XIX (Ostos, 2017, p.300). De modo geral, as sociedades vegetarianas incluíam nos estatutos a intenção de cessar a matança de animais, "demonstrar a inconveniência ... do morticínio cruel e desnecessário de toda espécie de animais úteis ou inofensivos e, enfim, todas as crueldades de qualquer natureza" (SNB, 6 out. 1913, p.4). Alguns vegetarianos engajaram-se na causa animal, participando dos dois movimentos. Consta como bibliotecário da Sociedade Brasileira Protetora dos Animais, do Rio de Janeiro, em 1915, o tenente Cicero dos Santos (SBPA, 1916, p.871). Acreditamos tratarse do militar de mesmo nome e patente que desde 1913 atuava na SVB. Outro vegetariano envolvido na causa foi Carlos Dias Fernandes, que publicou em 1914 o opúsculo "Proteção aos animais", tendo ministrado conferência com o mesmo título a convite da Sociedade Protetora dos Animais da Paraíba (Galvíncio, 2013, p.35, 101). Já Aleixo Alves de Souza, que chegou a presidente da Sociedade Naturista Brasileira, foi membro da Sociedade União Infantil Protetora dos Animais e um dos fundadores do Abrigo de Proteção aos Animais, no Rio de Janeiro (Suipa, 13 set. 1931, p.6; Abrigo..., 19 out. 1932, p.2).

Enquanto as sociedades vegetarianas faziam a defesa da vida animal pregando o fim do seu consumo como alimento, as agremiações de proteção aos bichos pouco defendiam a abstenção de carne, centrando seus esforços no combate à crueldade e aos maus-tratos contra eles praticados. O movimento vegetariano aplicava maior ênfase na questão da morte animal para uso humano, defendendo seu fim, enquanto os protetores dos bichos 
estavam empenhados em conquistar uma boa vida para eles. A defesa da vida animal pelos vegetarianos alinhava-se com a forte aspiração ao prolongamento da vida. A morte, quando chegasse, deveria vir por "causas naturais", tanto para humanos quanto para bichos. Na perspectiva do movimento, o vegetarianismo era o regime da vida, enquanto o carnivorismo expressaria pulsões destrutivas e de morte.

'Carnivorismo é uma civilização'. Pelo carnivorismo, o homem se tornou escravo da Doença, do Álcool, de todos os seus vícios. ... Não tem alma, tem ventre. ... O carnivorismo dá o punhal e ordena: 'Mata!'. O Naturismo dá o sorriso e pede: 'Colhe!'. ... atrás da morte e do sangue vem a miséria moral ... com o Naturismo, fala a Árvore da Vida (Olandim, nov. 1924; destaques nossos).

Para o autor, o carnivorismo implicava morte e sangue, já o naturismo apenas colhia, sem custo vital algum. A morte, como consequência negativa da alimentação, era aplicada aos seres tidos como complexos; desconsiderava-se o debate ético no caso dos viventes do reino vegetal. A expressão "carnivorismo é uma civilização" colocava o carnivorismo no registro da criação humana, enquanto o vegetarianismo, pré-social, estaria em sintonia com as leis da natureza (Twigg, 1981). O trecho insinua que, pela ingestão de carne, o homem perderia até sua alma, condição humana transcendental, reduzindo-se ao ventre, condição física elementar, como a de um bicho qualquer. A passagem faz referência à Árvore da Vida, símbolo importante da tradição judaico-cristã, citada na Bíblia quando se descreve o Jardim do Éden, onde, segundo o relato, homens e animais viveriam de forma pacífica, sem precisar matar para comer. Essa alegoria parece ter inspirado os propagandistas vegetarianos, pois ela aparece em outro artigo sobre o tema, configurada em uma imagem (Figura 1).

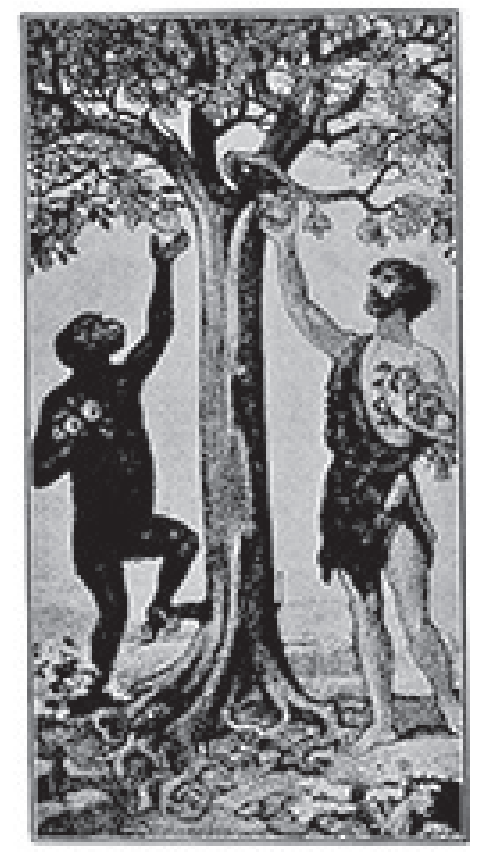

Figura 1: llustração da matéria "Os males que a carne nos faz" (Os males..., jan. 1918, p.56). 
Na figura, um homem e um macaco colhem frutas de uma mesma árvore. A legenda informa: "O homem primitivo era como o símio um frugívero; somente a necessidade durante o período glacial pode tê-lo obrigado a se alimentar com carne" (Os males..., 1918, p.56). A expressão "homem primitivo" se referia ao estágio original da humanidade, definindo uma verdade científica e histórica que deveria orientar o comportamento humano na atualidade. Passada a necessidade que teria obrigado o ser humano a ingerir carne, era necessário retornar ao estado natural. A alegoria é interessante porque ela permite o reconhecimento, na imagem, tanto daqueles alinhados com a tradição cristã, quanto dos conhecedores da árvore evolutiva de Darwin (2009, p.123), que na obra A origem das espécies, publicada originalmente em 1859, afirmou: "As afinidades entre todos os seres da mesma classe têm por vezes sido representadas através de uma árvore, e penso que é uma boa forma de representar a realidade". Dos vários animais que poderiam figurar na cena, foi escolhido o macaco, parecido com o homem, e que possuía especial relevo nos debates e controvérsias sobre a teoria da evolução de Darwin. Na imagem, as figuras expressam similaridade de posturas e gestos, enfatizando semelhanças que justificam a ideia proposta. Mas, ao mesmo tempo, o tronco da árvore é linear, separando e demarcando duas espécies em paralelo. O ser humano é representado por um homem branco, que se distingue do macaco pela ausência de pelos no corpo, pela sustentação ereta com os dois pés no chão e pela vestimenta (feita de peles), sinal de cultura. De acordo com Julia Twigg (1981), o motivo edênico perpassa as diferentes versões do vegetarianismo, mesmo as seculares, em que os aspectos religiosos foram substituídos pela ideia laica de uma natureza ecologicamente harmônica.

Apesar de a natureza ser enaltecida como fonte da verdade e de lições morais, os modelos que ela apresentava, no entanto, não eram igualmente valorizados pelo movimento vegetariano. O primeiro modelo oferecido pela natureza era positivo, o dos herbívoros. "O boi, não obstante ser um animal irracional, portanto inferior, tem mais inteligência do que muitos homens! Ele, por um secreto instinto odeia a carne ... Alimenta-se dos vegetais que lhe concederam a força, a paciência, o heroísmo e o amor! Ao invés de assassiná-lo sejamos vegetarianos, como ele" (Barros, 18 abr. 1920, p.2). Nessa passagem encontramos ideia recorrente nos discursos, de que animais, mesmo tendo direito à vida, eram considerados, de modo geral, inferiores ao homem, predominando a noção de assimetria entre as espécies. O segundo modelo encontrado no mundo natural era o dos carnívoros. Nas palavras do propagandista vegetariano Carlos Dias Fernandes (1918, p.43-44),

'Diz-me o que comes que te direi quem és'. Observemos um boi, por exemplo, que é um 'herbívoro ruminante' ... impressiona a sua energia; agradável até mesmo o odor das suas fezes; brando o seu caráter; dóceis os seus costumes. Já não apresenta uma onça os mesmos sinais. Possui dentes ameaçadores ... é inquieta e nervosa; destacam-se nas suas grandes patas unhas recurvas, é desconfiada e feroz, desprende-se do seu corpo um fétido insuportável. ...Todos os animais, que se alimentam dessa maneira, apresentam um característico comum: são 'ferozes' e 'sanguinários'; comprazem-se no assalto e devoração de outros bichos pacíficos como o veado .... Sendo a natureza a grande mestra de toda a sabedoria, devemos também consultá-la sobre a nossa alimentação; e da nossa dessemelhança do tigre e aproximação do macaco concluímos que são os frutos, as nozes, os grãos e as raízes o variado e sadio alimento que nos convém. 
A máxima "Diz-me o que comes que te direi quem és" expressava mais do que as consequências físicas do regime alimentar; indicava a correlação entre alimentação e comportamento positivo ou negativo. Segundo a fala, os herbívoros, pelo fato de comer vegetais, seriam mansos e tranquilos, destituídos de agressividade. Já os carnívoros, além de fisicamente repulsivos, foram qualificados como "sanguinários", isto é, excediam o registro da necessidade, deleitando-se na morte "de outros bichos pacíficos", os herbívoros. Se, como disse o autor, a natureza é mestra de toda a sabedoria, o trecho sugere que ela "resvalou" ao criar o carnívoro. Os aspectos do mundo natural que conflitavam com o ideal vegetariano eram quase um "erro" da natureza. O médico Gustavo Armbrust (18 dez. 1915, p.381), ao discorrer sobre as propriedades da carne, afirmou que "O envenenamento é tal, nos animais carnívoros, que a sua vida é curta, muito mais curta do que nos animais que se alimentam de vegetais". De acordo com esse registro, a "toxicidade cárnea" faria mal até mesmo para os bichos compelidos a tal dieta. O clínico se estendeu no assunto: “Os animais carnívoros são, geralmente, selvagens e perigosos, ao passo que os herbívoros deixam-se domesticar facilmente. ... Os ratos brancos, enquanto alimentados com pão ou grãos, são muito mansos, ao passo que ficam ferozes e selvagens, quando se lhes dá a carne como alimentação" (Armbrust, 5 fev. 1916, p.45-46).

A sugestão era de que os alimentos transmitiam, ou despertavam, comportamentos e qualidades morais nos seres vivos, humanos ou animais. Os herbívoros eram enaltecidos como "companheiros vegetarianos", de essência dócil e pacífica. Já os carnívoros, nos discursos analisados, expressavam uma natureza violenta e destrutiva, "Um comedor de cadáveres é necessariamente grosseiro, feroz e irascível, o vegetariano deve ser delicado, espiritual e sensível" (SNB, 16 dez. 1913, p.1). Para os humanos, comer carne apresentaria diversos perigos, constantemente elencados pelos ativistas. Impactaria a saúde, desencadeando doenças e desequilíbrios físicos, "A carne gera a sífilis e origina as doenças cardíacas, forma as patogenias nervosas" (Cavalcanti, 8 dez. 1919, p.1); "O carnivorismo é a causa principal do alcoolismo" (O Bem, nov. 1924). A dimensão espiritual também sofreria danos, pois a carne era considerada produto da morte e do sofrimento: "o 'magnetismo' da carne e dos objetos que custam a vida violentamente arrancada e as dores implícitas, é 'impuro'” (Abrigo..., 19 out. 1932, p.2). Além disso, a ingestão de proteína animal era tida como marco negativo na história da humanidade, desencadeando supostos processos civilizatórios negativos, "Os povos muito carnívoros são incontinentes, dão-se ao uso do álcool, do fumo, do ópio e outros entorpecentes requeridos pela corrupção palatal" (Fernandes, 31 jan. 1930, p.1). O caráter de toda uma cultura era julgado por esse critério, "Os povos que comem carne são mais ferozes que os outros" (O Bem, nov. 1924).

Por que, afinal, o humano carnívoro tenderia a formar e expressar qualidades tão negativas? A ideia subjacente nos discursos era de que a carne comunicava ao ser humano uma vitalidade animal negativa. Segundo Aleixo de Souza (jul. 1936, p.23), "O homem, ao alimentar-se de carne, absorve não só um alimento impróprio ao seu bem-estar físico, como também certas partículas sutis inerentes à mentalidade grosseira do animal, peculiares à sua organização sensorial obtusa". Para o ativista, presidente da Sociedade Naturista, ardoroso defensor da vida animal, comer carne era condenável, por fundar-se em um ato 
de sofrimento e egoísmo com relação a outros seres vivos, mas também por possibilitar uma comunicação perigosa, degradante, entre as essências animal e humana. No caso em pauta, o processo metabólico de assimilação da carne contaminaria a natureza humana com a natureza animal, vistas, não como positivamente diferentes, mas como assimétricas em termos de escala de valores. A abstenção de carne seria benéfica porque, além de respeitar a vida dos animais, preservaria a superioridade hierárquica humana, sua excepcionalidade em relação aos demais seres vivos. Nesse sentido, vegetarianismo e carnivorismo não representavam apenas opções dietéticas.

O fluxo de aproximação/positivo distanciamento/negativo que os discursos vegetarianos mantinham sobre os animais não é mera inconsistência lógica. O movimento vegetariano, essencialmente propositivo, buscava o convencimento sobre a legitimidade de suas ideias, de forma que a argumentação era ponto central de sua existência. Os discursos lançavam mão da retórica - entendida como técnica de composição da narrativa -, selecionando os enunciados mais adequados a cada enredo e contexto, sempre com o intuito de persuadir o interlocutor (Foucault, 2009, p.12). Se na sustentação das teses defendidas surgiam contradições, mais importante do que o conteúdo, era o 'efeito' do discurso, a eficácia em atrair o ouvinte. No âmbito da estratégia retórica, a pedagogia dos extremos funcionava bem, identificando a prática vegetariana com a virtude e o carnivorismo com o vício. Interessante é que tal divisão moral alcançava o reino animal.

O ser humano, que em situação ideal poderia escolher o que comer, deveria recusar a carne não apenas para poupar os animais, mas também para manter-se acima deles, afastando-se da cadeia de predação, que envolvia ataque, morte, sangue e sujeira (Lestel, 2016, p.47). "Como é possível conservar a noção do respeito e da dignidade, a consciência do Eu, após uma refeição que começa por uma sopa de 'rabo de boi?'” (O Bem, nov. 1924). Ao mencionar a "consciência do Eu" como qualidade essencialmente humana, o trecho retoma aspectos do debate filosófico ocidental que, desde o pensamento de René Descartes (2001, p.61-66) em $O$ discurso do método, publicado originalmente em 1637, instaurou a autoconsciência como aspecto definidor da superioridade dos homens em comparação aos animais. Para o ser humano, comer carne nunca poderia ser naturalizado, como expressa a imagem da Figura 2.

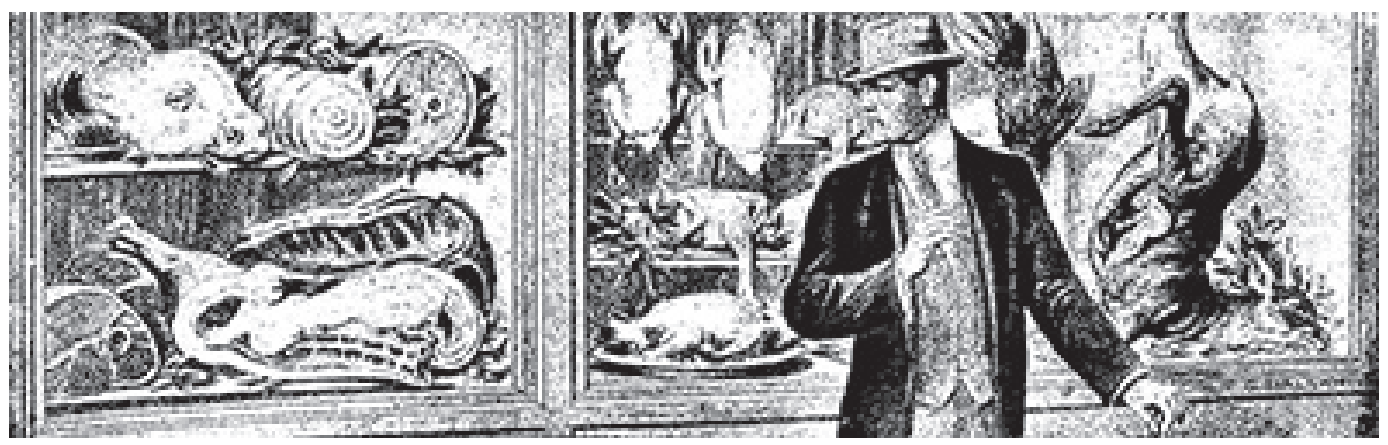

Figura 2: llustração da matéria "Os males que a carne nos faz" (Os males..., jan. 1918, p.55) 
O desenho mostra a vitrina de um açougue cujas prateleiras expõem pedaços de animais mortos, carne. O propósito do negócio seria atrair o cliente pela mostra caprichada dos produtos, mas a legenda indicava reação contrária, "A impressão que produz o aspecto de uma casa de comestíveis animais: - Repugnância" (Os males..., jan. 1918, p.55). A composição opta por mostrar corpos de animais inteiros ou partes grandes e discerníveis, de modo que o leitor não possa escapar do fato de que carne é o cadáver de um animal. $\mathrm{O}$ veado exposto com a barriga aberta, a cabeça inteira de um boi cujo olhar triste se direciona ao espectador, as aves sem cabeça, são argumentos imagéticos que visam ressaltar o grotesco. Segundo Norbert Elias (1994, p.128; destaque no original), "é característico de todo o processo que chamamos de civilização esse movimento de segregação, esse ocultamento 'para longe da vista' daquilo que se tornou repugnante", incluindo a exposição de carcaças e a morte de animais, cenas inadequadas diante de novos parâmetros de civilidade, fundados no progressivo refinamento dos costumes e sentidos. A imagem negava esse conforto, e em vez de cortes de carne pequenos, amorfos, a presença animal foi ampliada. O homem, de costas para a vitrine, repudiava o quadro; suas vestes elegantes reforçavam o argumento de que pessoas "civilizadas" não se contaminavam com a carne nua e crua, permanecendo do lado da cultura.

Comer animais, nos discursos vegetarianos da época, não era apenas uma injustiça contra os bichos. Era também a equiparação do ser humano com o animal em sua "pior" versão, de besta-fera, cuja necessidade de consumir outros animais revelaria uma essência negativa, à qual o homem não deveria se render: "E perderemos assim o ódio que se entranha nos carnívoros ... não teremos mais a constante ira que acende o carnivorismo nos seus adeptos! ... Vilipendiemos pois, a alimentação das hienas e dos chacais! Convertamo-nos ao vegetarianismo - o regime da paz e da ventura!" (Barros, 18 abr. 1920, p.2). Por mais que os discursos dos propagandistas vegetarianos enaltecessem a natureza, sua organização e suas "leis", existia um profundo desconforto diante dos aspectos mais duros do mundo natural, a predação, a morte, a competição, o conflito, a indiferença com a sorte do outro na disputa pela sobrevivência. Os animais herbívoros eram representados como destituídos de qualquer traço de agressividade, encarnando a ideia de uma natureza pacífica (ainda assim, eram tidos como inferiores ao ser humano). Já os carnívoros figuravam, nos discursos mais fortes, como seres decaídos, seus instintos seriam aviltantes para si mesmos e para o mundo, como argumentou o ativista Carlos Fernandes (31 jan. 1930, p.1): “o carnivorismo, mesmo entre as feras, é um hábito contrário à harmonia do cosmo, resultando funesto aos animais que o praticam, todos marcados pelo odor nauseabundo que exalam, pelas úlceras que soem apresentar e das quais ordinariamente fenecem".

Assim, nem todos os discursos do movimento vegetariano eram simpáticos aos animais, alguns eram abertamente hostis. A vida era o critério genérico que irmanava os seres, mas, a partir daí, suas diferenças demarcavam hierarquias, e no topo da escala valorativa estava o ser humano. O homem, ao abster-se de carne, salvava a si mesmo, elevando-se do nível da "animalidade negativa". Essa "animalidade negativa" estaria presente na própria carne, que, pela ingestão, poderia comunicar às pessoas características inferiores dos animais, e também na ação de predar/matar, típica dos carnívoros, depreciados em parte dos discursos vegetarianos. 


\section{Considerações finais}

Percebemos, a partir do recorte temático e das fontes, que o ativismo vegetariano da época lidava com seus próprios paradoxos: defesa do direito à vida dos bichos, mas afirmação da excepcionalidade e superioridade humana em relaçãoaos animais; reconhecimento de profundas semelhanças biológicas/naturais entre os seres humanos e os animais, ponto central para defesa científica e moral do vegetarianismo, mas negação das similaridades quando desalinhadas com os princípios que defendiam; visão positiva dos bichos, mas não necessariamente extensiva a todos, principalmente os carnívoros.

Os ativistas possuíam uma perspectiva idealizada da natureza. Como homens urbanos da camada média eles tinham contato, em grande parte, com um mundo natural controlado. O distanciamento das práticas de produção, seja na lida com os animais ou na lavoura, colaborava para a construção de extremos: a criação de animais seria sempre cruel, e o cultivo da terra, além de agradável, se fazia em harmonia com a natureza. A idealização da natureza também se expressava na crença de que ela favorecia apenas a vida, a integridade física e a longevidade dos seres. Morrer era natural e inevitável, mas matar para alimentar-se, não. Nesse sentido, o vegetarianismo seria "O elixir da longa vida" (SNB, 16 dez. 1913, p.1), preservando a existência dos animais e prolongando a humana. Em tal dinâmica, fazer os bichos viver era ajudar a expurgar a morte no mundo, daí que as sociedades vegetarianas da época não centrassem seus esforços na promoção da "qualidade" de vida animal, e sim em evitar sua morte. A crueldade era repudiada, por representar o sofrimento inaceitável dos bichos e também por equiparar o ser humano à suposta "crueldade" dos carnívoros, que na caça/predação causavam morte, dor, aflição, agonia e derramamento de sangue.

Não por acaso, a carne - tão comumente associada no imaginário cristão ao pecado, sendo os chamados "pecados da carne" aqueles relacionados à dimensão corpórea - era considerada pelos propagandistas vegetarianos porta de entrada para vícios físicos: alcoolismo, glutonaria, violência. A "essência animal" contida na carne contaminaria o humano, equiparando-o ao bicho em sua projeção mais temida: irracional, inconsciente, descontrolado em seus apetites. Como afirmou Norbert Elias (1994, p.128; destaque no original), "as pessoas, no curso do processo civilizatório, procuram suprimir em si mesmas todas as características que julgam 'animais'”. Nos discursos vegetarianos da época, os bichos que mais agregavam qualidades negativas eram os carnívoros, alvo de diversas assertivas moralizadoras.

Notamos, nessas projeções antropocêntricas, o anseio subjacente de redesenhar a natureza, aproximando-a de uma versão idealizada, em que o ciclo da vida se daria sem morte infligida por outro ser, tensão, dor, perda e conflito. Isso não implica afirmar que o movimento vegetariano do período não fizesse a defesa sincera dos animais, instando a sociedade a refletir sobre as bases éticas da ingestão de carne e o uso indiscriminado de outros seres para benefício humano, sem limite ou responsabilização. Nesse registro, o direito à vida era tido como universal (exceto para o reino vegetal), mas a fronteira entre o humano e o animal continuava delimitada pela superioridade humana. Percebemos que os discursos estudados, no que se refere à representação dos animais, abriam uma brecha no horizonte ético do movimento vegetariano da época: a permissão para que o homem reformasse a natureza em seus aspectos "equivocados", em particular o comportamento 
animal, com o intuito de elevar os bichos, especialmente os carnívoros, de sua própria "animalidade negativa", recriando um "animal melhor", que vivesse de acordo com parâmetros morais humanos.

\section{AGRADECIMENTOS}

Agradeço aos colegas do Centro de Estudos dos Animais (CEA), linha Ciência, Natureza, Animais e Território, do grupo de pesquisa Coleção Brasiliana/Fafich/UFMG, pela interlocução. Especialmente à coordenadora do CEA, Regina Horta Duarte. Agradeço à Fiocruz Minas, à Fiotec pelo financiamento, aos pareceristas anônimos, a Henrique Costa, pelo trato das imagens, e à Biblioteca Nacional pelo inestimável serviço de disponibilização de documentos digitais.

\section{NOTAS}

${ }^{1}$ Nessa e nas demais citações em idioma estrangeiro a tradução é livre.

${ }^{2}$ O termo veganismo surgiu na década de 1940, na Inglaterra, para designar os praticantes que excluíam não apenas a carne da alimentação, como qualquer produto de origem animal da dieta, do vestuário e de quaisquer outras formas de uso (Preece, 2008, p.297-298).

\section{REFERÊNCIAS}

ABRAMS, H. Leon. Vegetarianism: another view. In: Kiple, Kenneth; Ornelas, Kriemhild Coneè (ed.). The Cambridge world history of food, v.2. Cambridge: Cambridge University Press, 2000. p.1564-1573.

ABRIGO de Proteção aos Animais. Diário da Noite, n.838, p.2, 19 out. 1932.

ALONSO, Angela Maria. De positivismo e de positivistas: correntes positivistas brasileiras e o caso Pereira Barreto. In: Encontro Anual da Associação Nacional de Pós-graduação e Pesquisa em Ciências Sociais, 19., Caxambu. Anais... São Paulo: Anpocs, 1995. p.1-20. Disponível em: http://www.anpocs.com/index. php/encontros/papers/19-encontro-anualda-anpocs/gt-18/gt22-13/7708-angelaalonsopositivismo/file. Acesso em: 3 out. 2020.

ARMBRUST, Gustavo. Higiene dietética: noções de higiene alimentar (continuação). O Brasil Médico, n.7, p.53-55, 12 fev. 1916.

ARMBRUST, Gustavo. Higiene dietética: noções de higiene alimentar (continuação). O Brasil Médico, n.6, p.45-46, 5 fev. 1916.

ARMBRUST, Gustavo. Higiene dietética: noções de higiene alimentar. O Brasil Médico, n.48, p.377-381, 18 dez. 1915.

ASSOCIAÇÕES: Sociedade Vegetariana Brasileira. O Paiz, n.12068, p.3, 24 out. 1917.

BARROS, Eudes. O vegetarianismo e Carlos D. Fernandes. O Norte, n.3448, p.2, 18 abr. 1920.
BARTHE-DELOIZY, Francine. Le naturisme. Communications, n.74, p.49-64, 2003.

BERNARDINO, Maria Gabriela. O mapa como elemento do progresso: um breve ensaio sobre Francisco Jaguaribe de Mattos e a Carta de Mato Grosso (1910-1922). In: Encontro de História da Anpuh-Rio, 17., 2016, Nova Iguaçu. Anais... Rio de Janeiro: Associação Nacional de História/ Seção Rio de Janeiro, 2016. p.1-9. Disponível em: http://www.encontro2016.rj.anpuh.org/ resources/anais/42/1466961776_ARQUIVO_ TrabalhoAnpuh-MG.pdf. Acesso em: 15 set. 2020.

BEZERRA, José Arimatea Barros. Educação alimentar e a constituição de trabalhadores fortes, robustos e produtivos: análise da produção científica em nutrição no Brasil, 19341941. História, Ciências, Saúde - Manguinhos, v.19, n.1, p.157-179, 2012.

BOLETIM bibliográfico: o vegetarismo. O Brasil Médico, n.33, p.266-267, set. 1895.

BRAGA, Isabel Drumond. Em busca do novo Éden no século XX: os portugueses e a fundação de colônias naturistas no Brasil. História, Ciências, Saúde-Manguinhos, v.25, n.3, p.659678, 2018.

BRASIL. Ministério da Agricultura, Indústria e Comércio. Diretoria Geral de Estatística. Anuário estatístico do Brasil, 1908-1912, v.2: economia e finanças. Rio de Janeiro: Tipografia da Estatística, 1917. Disponível em: https://biblioteca.ibge.gov. br/visualizacao/periodicos/20/aeb_1908_1912_ v2.pdf. Acesso em: 7 mar. 2020. 
CARNEIRO, Trajano Bruno de Berredo. [Depoimento]. Entrevistadores: Celso Castro, Mônica Kornis. Rio de Janeiro: Centro de Pesquisa e Documentação de História Contemporânea do Brasil. 3 fitas cassete (2h10min). Depoimento concedido ao Projeto Trajetória e Desempenho das Elites Políticas Brasileiras, 30 set. 1993. Disponível em: http:// www.fgv.br/cpdoc/acervo/historia-oral/ entrevista-tematica/trajano-carneiro. Acesso em: 4 fev. 2020.

CASTRO, Josué de. Geografia da fome: o dilema brasileiro: pão ou aço. Rio de Janeiro: Antares, 1984.

CAVALCANTI, de Hollanda. Falenas: a questão da carne. O Estado, n.1379, p.1, 8 dez. 1919.

CORTON, Paul. O regime cárneo atenuado e o regime vegetariano: "Leis da vida sã". O Bem, n.1, nov. 1924 .

DARWIN, Charles. A origem das espécies: através da seleção natural ou a preservação das raças favorecidas na luta pela sobrevivência. Leça da Palmeira: Planeta Vivo, 2009.

DESCARTES, René. Discurso do método. São Paulo: Martins Fontes, 2001.

DOUGLAS, Mary. Pureza e perigo. São Paulo: Perspectiva, 1976.

DR. JACOBSON. Dieta vegetal. O Fluminense, n.9334, p.2, 12 nov. 1914.

ELIAS, Norbert. O processo civilizador, v.1: uma história dos costumes. Rio de Janeiro: Jorge Zahar, 1994.

FERNANDES, Carlos Dias. A carne como alimento. O País, n.16539, p.1, 31 jan. 1930.

FERNANDES, Carlos Dias. O regime alimentar. O Naturista, n.2, p.43-44, 1918.

FIDDES, Nick. Meat: a natural symbol. New York: Routledge, 2004.

FOUCAULT, Michel. Le courage de la vérité: le gouvernement de soi et des autres: cours au Collège de France, 1984. Paris: Seuil, 2009.

FOUCAULT, Michel. A arqueologia do saber. Rio de Janeiro: Forense Universitária, 2004.

FUDGE, Erica. Animal. London: Reaktion Books, 2002.

GALVÍNCIO, Amanda Sousa. Atuação educacional de Carlos Dias Fernandes na Parahyba do Norte (1913-1925): jornalismo, literatura e conferências. Dissertação (Mestrado em Educação) - Universidade Federal da Paraíba, João Pessoa, 2013.
GAZETADE NOTÍCIAS, n.16, p.8, 16 jan. 1916.

GREGORY, James. Of Victorians and vegetarians: the vegetarian movement in nineteenth-century Britain. London: Tauris Academic Studies, 2007.

INICIATIVA útil. O País, n.12061, p.2, 17 out. 1917. JANTAR. Jornal do Commercio, n.317, p.7, 15 nov. 1919.

LEMOS, Miguel. Positivismo e vegetarismo. Apostolado Positivista do Brasil, n.213, p.1-12, nov. 1902. Disponível em: http://www.fgv.br/ cpdoc/acervo/arquivo-pessoal/IP/impresso/ positivismo-e-vegetarismo. Acesso em: 5 set. 2020.

LESTEL, Dominiqui. Eat this book: a carnivore's manifesto. New York: Columbia University Press, 2016.

LÉVI-STRAUSS, Claude. A lição de sabedoria das vacas loucas. Estudos Avançados, v.23, n.67, p.211-216, 2009.

LIMA, Eronides da Silva. Gênese e constituição da educação alimentar: a instauração da norma. História, Ciências, Saúde - Manguinhos, v.5, n.1, p.57-84, 1998.

LUCA, Tânia Regina de. Fontes impressas: história dos, nos e por meio dos periódicos. In: Pinsk, Carla Bassanezi (org.). Fontes históricas. São Paulo: Contexto, 2008. p.111-154.

MACIEL, Maria Eunice. Uma cozinha brasileira. Estudos Históricos, n.33, p.25-39, 2004.

NATURISMO. O Naturista, n.1, p.6-7, 24 jun. 1936.

NÚCLEO Naturista Maranhense. O Jornal, n.878, p.4, 2 out. 1917.

BEM. Rio de Janeiro, n.1, nov. 1924.

OLANDIM, F. Filosofia naturista. O Bem, n.1, nov. 1924.

OS MALES que a carne nos faz. Eu Sei Tudo, n.8, p.54-56, jan. 1918.

OSTOS, Natascha Stefania Carvalho de. União Internacional Protetora dos Animais de São Paulo: práticas, discursos e representações de uma entidade nas primeiras décadas do século XX. Revista Brasileira de História, v.37, n.75, p.297-318, 2017.

OTTER, Chris. Planet of meat: a biological history. In: Bennett, Tony (ed.). Challenging (the) humanities. Canberra: The Australian Academy of the Humanities, 2013. p.1-19.

PEIXOTO, Afranio. Consultas médicas: constipação habitual. O Brasil Médico, n.16, p.155-157, 22 abr. 1908. 
PELAS ASSOCIAÇÕES: Sociedade Naturista Brasileira. A Noite, n.1798, p.5, 19 dez. 1916.

PREECE, Rod. Sins of the flesh: a history of ethical vegetarian thought. Vancouver: UBC Press, 2008.

QUÉDRAOGO, Arouna. De la secte religieuse à l'utopie philantropique: genèse sociale du végétarisme occidental. Annales. Histoire, Sciences Sociales, n.4, p.825-843, 2000.

ROCHA, Lucas Vinicius Erichsen da. História desanima(liza)da: os matadouros da cidade do Rio de Janeiro, 1777-1881. Tese (Doutorado em História) - Universidade Federal do Rio de Janeiro, Rio de Janeiro, 2020.

SÁ, Dominichi Miranda de. A ciência como profissão: médicos, bacharéis e cientistas no Brasil, 1895-1935. Rio de Janeiro: Editora Fiocruz, 2006.

SANTOS, Cícero dos. O aberrante padrão alimentar do carioca. O Naturista, n.9-10-11-12, p.30-32, 1937.

SANTOS, Cícero dos. A questão alimentar na melhoria da alimentação do povo Brasiliense. $O$ Naturista, n.1, p.9-10, 24 jun. 1936.

SBPA, Sociedade Brasileira Protetora dos Animais. Almanak Laemmert: administrativo, mercantil e industrial, v.1, n.72, p.871, 1916.

S.M.B. Variedades: o frugivorismo do homem primitivo. O Brasil Médico, n.9, p.197-198, 29 fev. 1936.

SMC, Sociedade de Medicina e Cirurgia. O Brasil Médico, n.44, p.350-351, 20 nov. 1915.

SNB, Sociedade Naturista Brasileira. A República, n.282, p.1, 16 dez. 1913.

SNB, Sociedade Naturista Brasileira. OImparcial, n.306, p.4, 6 out. 1913.

SUIPA, Sociedade União Infantil Protetora dos Animais. Correio da Manhã, n.11272, p.6, 13 set. 1931.

SVB, Sociedade Vegetariana Brasileira: segunda conferência pública. O Imparcial, n.11770, p.4, 16 nov. 1917.
SVB, Sociedade Vegetariana Brasileira. Jornal do Commercio, n.205, p.8, 25 jul. 1917.

SOUSA, Oscar Frederico de. Necrologia. O Brasil Médico, n.33, p.575-576, 16 ago. 1941.

SOUZA, Aleixo Alves de. O elogio dos frutos. $O$ Naturista, n.2, p.21-24, jul. 1936.

SOUZA, Aleixo Alves de. Em prol dos animais. Diário de Notícias, n.481, p.18, 11 out. 1931.

STUART, Tristram. The bloodless revolution: radical vegetarians and the discovery of India. London: Harper, 2006.

THOMAS, Keith. O homem e o mundo natural: mudanças de atitude em relação às plantas e aos animais, 1500-1800. São Paulo: Companhia das Letras, 1988.

TWIGG, Julia. The vegetarian movement in England, 1847-1981: a study in the structure of its ideology. Tese (Doutorado) - London School of Economics, London, 1981. Disponível em: https://ivu.org/history/thesis/nature2.html. Acesso em: 15 dez. 2020.

UM HÓSPEDE original. A Capital, n.169, p.1, 4 jan. 1918.

VARGAS, Jonas Moreira. Abastecendo 'plantations': A inserção do charque fabricado em Pelotas (RS) no comércio atlântico das carnes e a sua concorrência com os produtores platinos (século XIX). História, v.33, n.2, p.540-566, 2014.

VASCONCELOS, Francisco de Assis Guedes de. Tendências históricas dos estudos dietéticos no Brasil. História, Ciências, Saúde - Manguinhos, v.14, n.1, p.197-219, 2007.

VENTURA, Roberto. Estilo tropical: história cultural e polêmicas literárias no Brasil, 1870-1914. São Paulo: Companhia das Letras, 1991.

WHORTON, James. Vegetarianism. In: Kiple, Kenneth; Ornelas, Kriemhild Coneè (ed.). The Cambridge world history of food, v.2. Cambridge: Cambridge University Press, 2000. p.1553-1563.

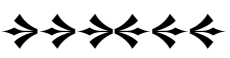

